\title{
Estimasi Perbandingan Efisiensi Saham di Perusahaan Industri menggunakan Metode DEA Solver dengan Model CCR
}

\author{
Yuli Fitriyani ${ }^{1)}$, Insan Kamil' ${ }^{2)}$ \\ Jurusan Akuntansi, Politeknik Negeri Tanah Laut \\ 1)yulihazami@politala.ac.id, ${ }^{2)}$ kamilinsan200398@gmail.com
}

\begin{abstract}
Abstrak
Penelitian ini menggunakan metode Data Empelopment Analysis (DEA) yang merupakan sebuah metode kuantitatif non parametik yang dapat digunakan untuk menganalisis kinerja ataupun untuk menilai tingkat efisiensi dan membandingkannya dari setiap Decision Making Unit (DMU). DMU dinyatakan sudah mencapai tingkat efisiensi relatif jika sudah mencapai nilai 1 atau $100 \%$ dan semakin tidak efisiensi jika semakin jauh dari nilai 1 atau $100 \%$. Penelitian ini untuk menganalisis efisiensi perusahaan makanan dan minuman di Indonesia menggunakan metode DEA dengan model CCR. Model CCR atau (Charner, Cooper, dan Rhodes) dimana metode DEA Solver ini biasanya digunakan untuk menilai tingkat efisiensi relatif dengan terlebih dahulu menentukan karakteristik dari setiap katagori atau DMU tersebut. Hasil dari penelitian tersebut menunjukan bahwa terdapat 2 DMU yang memiliki tingkat efisiensi 1 dan 3 DMU yang tidak efisiensi.
\end{abstract}

Kata kunci: DEA, DMU, CCR, Makan dan Minuman

Abstract

This study uses the Data Empowerment Analysis (DEA) method which is a quantitative non parametric method that can be used to analyze performance or to assess the level of efficiency and compare it from each Decision Making Unit (DMU). The DMU is stated to have reached a level of relative efficiency if it has reached a value of 1 or $100 \%$ and is increasingly not efficient if it is getting far from the value of 1 or $100 \%$. This study is to analyze the efficiency of food and beverage companies in Indonesia using the DEA method with the CCR model. The CCR model (Charner, Cooper, and Rhodes) where the DEA Solver method is usually used to assess the level of relative efficiency by first determining the characteristics of each category or DMU. The results of the study show that there are 2 DMUs that have efficiency levels 1 and 3 that are not efficient.

Keywords: DEA, DMU, CCR, Food and Beverage

\section{PENDAHULUAN}

Industri makanan dan minuman di Indonesia memiliki peran yang sangat penting dalam pertumbuhan ekonomi, karena dalam sektor makanan dan minuman adalah sektor yang diprioritaskan oleh Pemerintah dalam mendorong industri sebagai penggerak ekonomi nasional. Berbagai macam produk yang diciptakan dalam sektor makanan dan minuman seperti produk mie yang tiap tahun semakin meningkat jumlah produksi dan peminatnya, bukan produk mie saja yang semakin tahun meningkat, produk minuman berbotol yang beraneka rasa tidak kalah dalam persaingan industri.

Perusahaan dalam sektor makanan dan minuman ini secara tidak langsung menciptakan lowongan pekerjaan yang membantu masyarakat yang tidak memiliki pekerjaan, jika dalam sektor ini banyak yang mengalami kebangkrutan maka akan ada jutaan orang yang kehilangan pekerjaan dan berdampak pada meningkatnya angka pengangguran di Indonesia bukan itu saja tetapi juga berpengaruh pada kebutuhan dalam hal makanan dan minuman di Indonesia.

Perkembangan bisnis makanan dan minuman terjadi akibat adanya perubahan pola hidup dari konsumen yang memiliki jadwal kerja padat, sehingga konsumen tersebut mencari tempat yang bisa membuat konsumen tersebut menjadi rileks.

Berdasarkan tujuan penelitian tersebut yakni untuk mengetahui estimasi atau perkiraan tingkat efisiensi saham perusahaan makanan dan minuman di Indonesia. Oleh sebab itu, kami disini menggunakan metode DEA (Data Envelopment Analysis) dengan model CCR (Charner, 
Cooper, dan Rhodes), biasanya metode DEA ini sering digunakan untuk melakukan pengukuran atau meneliti tingkat efisiensi relatif dengan terlebih dahulu menentukan karekteristik setiap kategori atau DMU (Decision Making Unit) yang terdiri dari input maupun output, dimana DMU tersebut ialah objek yang akan diteliti tingkat efisiensinya dan penelitian ini yang menjadi DMU nya adalah Perusahaan yang bergerak dalam bidang industri berupa sektor makanan dan minuman yang ada di Indonesia.

Metode DEA (Data Envelopment Analysis) adalah suatu metode nonparametrik yang digunakan untuk menilai tingkat efisiensi relatif Decision Making Unit (DMU), untuk memperoleh nilai tingkat efisiensi dari DMU yang akan dibandingkan, dengan pengolahan data menggunakan Software Banxia Frontier Analyst 3 dan Software maxdea. Suatu DMU akan dinyatakan telah mencapai efisiensi relatif jika mencapai nilai 1 atau 100\% dan semakin tidak efisiensi jika semakin jauh dari nilai 1 atau 100\%. (Kholis Ernawati, dkk, 2015)

Menurut (Walter, 1995), pengertian efisiensi ada dua dilihat dari teori ekonomi yaitu efisiensi ekonomi dan efisiensi teknis. Efisiensi ekonomis mempunyai sudut pandang mikro yang mempunyai jangkauan lebih luas dibandingkan dengan efisiensi teknis yang bersudut pandang makro yang mempunyai jangkauan lebih luas dibandingkan dengan efisiensi teknis yang bersudut pandang mikro. Pengukuran efisiensi teknis cenderung terbatas pada hubungan teknis dan operasional dalam proses konversi input menjadi output. Akibatnya, usaha untuk meningkatkan efisiensi teknis hanya memerlukan kebijakan mikro yang bersifat internal.

Meningkatnya harga barang-barang kebutuhan produksi yang diakibatkan oleh inflasi dan faktor lainnya, menuntut perusahaan untuk melakukan tindakan tepat guna memaksimalkan output yang dapat diraih demi menjamin keberlangsungan perusahaan dalam kancah persaingan nasional maupun internasional. Sebagai perusahaan yang sudah terjamin kehalalannya, maka perusahaan sub sektor makanan dan minuman yang telah terdaftar dalam ISSI (Indeks Saham Syariah Indonesia) (Mutohharo, 2017).

Perubahan harga saham di bursa atau di pasar sekunder dipengaruhi oleh beberapa faktor, antara lain yaitu faktor fundamental perusahaan, keuntungan yang diperoleh dari operasi perusahaan dengan jumlah investasi atau aktiva yang digunakan untuk operasional perusahaan (Nugroho J. Setiadi, dkk, 2012).

Perusahaan makanan dan minuman dalam hal keputusan modal berkaitan dengan sumber dana, baik yang berasal dari internal maupun dari eksternal perusahaan. Struktur modal adalah hasil atau akibat dari keputusan pendanaan yang intinya memilih apakah akan menggunakan utang ekuitas untuk mendanai operasi perusahaan, pilihan penggunaan utang atau ekuitas mengandung risiko yang berpengaruh terhadap nilai perusahaan sehingga pemilihan sumber dana eksternal harus berhati-hati karena masing-masing mempunyai kelebihan dan kelemahan. (Rambe, 2013) (Afrinda, 2013).

Usaha dalam sektor makanan dan minuman tersebut mengalami pertumbuhan di Indonesia yang cukup drastis, jika perusahaan memutuskan modal kerja dalam jumlah yang besar kemungkinan tingkat likuiditas akan terjaga namun kesempatan untuk memperoleh laba yang besar akan menurun pada akhirnya berdampak pada menurunnya profitabilitas (Nidya Afrinda, 2013).

Rasio profitabilitas untuk mengukur kemampuan suatu perusahaan dengan keseluruhan dana yang ditanamkan dalam aktiva digunakan untuk menghasilkan keuntungan, semakin tinggi pengambilan investasi akan dapat membuat ketertarikan bagi para investor sehingga nilai perusahaan akan semakin meningkat dengan sendirinya seiring dengan mengalirnya uang ke perusahaan yang bersangkutan (Suriani Ginting, dkk, 2013). 


\section{METODE PENELITIAN}

Metode DEA Solver merupakan suatu metode kuantitatif non parametik yang bisa digunakan untuk menganalisis kinerja berbagai jenis entitas atau perusahaan yang terlibat dalam berbagai aktivitas, didalam DEA Solver terdapat sampel yang disebut dengan Decision Making Unit (DMU) agar bisa membandingkan kinerja atau tingkat efisiensi dari DMU yang lain. Tingkat yang memiliki efisiensi 100\% yang mana bisa dijadikan tolak ukur bagi DMU yang lain untuk menentukan langkah-langkah perbaikan. Maka dari itu, kami disini menggunakan metode DEA Solver dengan model CCR (Charner, Cooper, dan Rhodes) untuk mengetahui seberapa besar tingkat efisiensi dengan mengambil obyek penelitian berupa perusahaan industri di bidang sektor makanan dan minuman di Indonesia pada tahun 2017.

Penggunaan Metode DEA Solver dalam penelitian ini langkah pertama yaitu mengumpulkan semua data-data dari 5 persentase saham perusahaan makanan dan minuman yang ada di Indonesia. Setelah itu, memprediksi atau memasukkan 4 karakteristik data input dan 6 karakteristik data output, kemudian memilih model yang ada dan memilih file data yang telah dibuat, selanjutnya di $R U N$ (dijalankan). Terdapat disana ada Summary (lembar kerja yang menunjukkan statistik data dan laporan ringkasan dari hasil yang diperoleh), Score (lembar kerja yang menunjukkan nilai atau score dan merangking DMU yang ada tetapi masih belum berurutan dan juga terdapat nilai average, nilai minimal, nilai maksimal, dan nilai standar devisiasi), Weight (data yang dibuat), Weight Data (data yang sudah dibuat), Rank (data sudah tersusun mulai ranking tertinggi sampai terendah), Graph 1 (grafik ini menunjukkan diagram batang dari score 5 DMU tersebut, namun grafik tersebut masih belum tersusun), Graph 2 (grafik batang ini sudah tersusun mulai score tertinggi sampai score terendah), Projection (lembar kerja ini berisikan proyeksi atau gambaran dari setiap DMU mengenai data yang dianalisis), Slack (lembar kerja ini berisi kelebihan input dan kekurangan output untuk setiap masing-masing DMU). Penelitian ini menyajikan model CCR untuk menganalisis tingkat efisiensi perusahaan makanan dan minuman di Indonesia dengan menggunakan metode DEA Solver. Penelitian yang menggunakan model CCR, dengan rumus di bawah ini:

Rumus model CCR:

Nilai untuk maksimum

$$
\begin{gathered}
\text { Max } \mathrm{Z}=\sum_{j=1}^{J} V_{j m} y_{j m} \\
\text { Ke subjek } \\
\sum_{i=I}^{I} U_{i m} X_{i m} \\
\sum_{i=I}^{I} V_{i m} y_{i m}-\sum_{i=I}^{I} U_{i m} X_{i m} \leq 0 ; n=1,2 \ldots, N \\
V_{j m}, U_{j m} \geq 0 ; \quad i=1,2, \ldots, I=1,2, \ldots J
\end{gathered}
$$

Nilai untuk minimum

$$
\operatorname{Min} \theta-\varepsilon\left(\sum_{i=1}^{m} S_{i}^{-}+\sum_{r=1}^{s} S_{r}^{+}\right)
$$

Ke subjek 


$$
\begin{gathered}
\sum_{j=1}^{m} X_{i j} \lambda_{j}+S_{i}^{-}=\theta X_{i o} \quad i=1,2, \ldots, p \\
\sum_{j=1}^{n} y_{r j} \lambda_{j}-S_{-}^{+}=y_{r o} \quad r=1,2, \ldots, q \\
\lambda_{j} \geq 0 \quad j=1,2, \ldots, n
\end{gathered}
$$

\section{HASIL}

Data yang kami dapatkan dari situs Yahoo Finance yang digunakan untuk mengetahui tingkat efisiensi dari 5 perusahaan makanan dan minuman di Indonesia pada tahun 2017. Penelitian dengan menggunakan model DEA Solver metode CCR, dimana dari model tersebut kami memaparkan 4 input yaitu: GDP, suku bunga, inflasi dan kurs, selain itu juga terdapat 6 output yaitu: Open, High, Low, Close, Adj Close dan Volume.

Dari data tersebut dengan menggunakan model CCR terlihat perbedaannya dari kedua model tersebut, agar mengetahui perbandingan tingkat efisiensi kedua model tersebut dari perusahaan makanan dan minuman di Indonesia. Terlihat di bawah ini tabel yang kami berikan:

TABEL 1

SCORE DAN NILAI AVERAGE, MAX, MIN, STANDAR DEVIASI DARI MODEL CCR

\begin{tabular}{|l|l|l|l|}
\hline No. & DMU & Score & Rank \\
\hline 1 & INDF & 1 & 1 \\
\hline 2 & ULTJ & 1 & 1 \\
\hline 3 & SKBM & 0,9925 & 4 \\
\hline 4 & PSDN & 0,999 & 3 \\
\hline 5 & ROTI & 0,9868 & 5 \\
\hline
\end{tabular}

\begin{tabular}{|l|l|}
\hline Average & 0,9957 \\
\hline Max & 1 \\
\hline Min & 0,9868 \\
\hline St Dev & 0,0059 \\
\hline
\end{tabular}

Sumber: Pengolahan Data DEA SOLVER

Terlihat dari Tabel kedua model diatas, model CCR terdapat 2 perusahaan yang memiliki tingkat efisiensi 1 , sedangkan tingkat efisiensi yang terendah yaitu 0,9868 . Hasil dari penelitian tersebut terdapat juga rata-rata sebesar 0,9957 , nilai maksimum 1 , nilai minimum 0,9868 dan terakhir nilai standar deviasi sebesar 0,0059, dari data tersebut terlihat perbandingan saham dari ke 5 saham tersebut. DMU yang memiliki tingkat efisiensi 1 yaitu INDF dan ULTJ, ranking 3 DMU PSDN dengan tingkat efisiensi 0,999, ranking 4 DMU SKBM dengan tingkat efisiensi 0,9925, dan yang terakhir DMU ROTI dengan tingkat efisiensi 0,9868. 


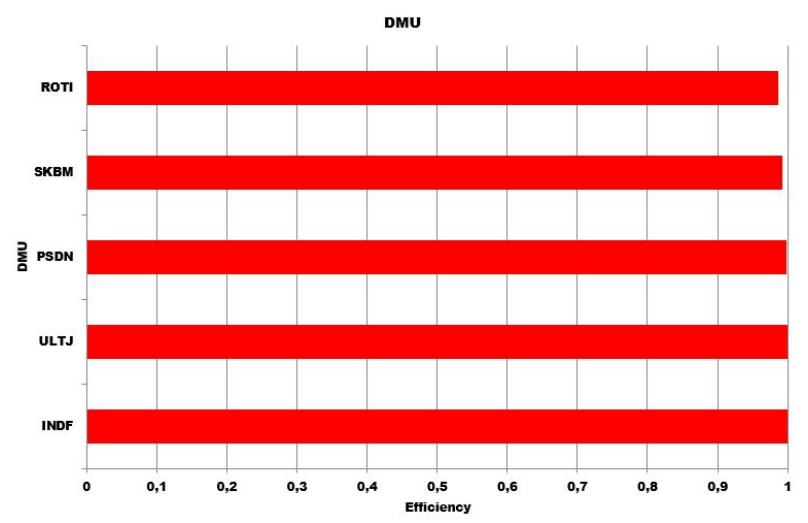

Grafik 1. Tingkat Efisiensi DMU Model CCR (Sumber: Pengolahan Data DEA Solver)

Berdasarkan dari data kedua Grafik di atas dengan tingkat efisiensi 1, bahwa kedua model tersebut memiliki tingkat efisiensi sama yaitu pada DMU INDF dan DMU ULTJ, dan untuk efisiensi yang terendah tersebut yaitu pada DMU ROTI. Terlihat dari grafik tersebut pembeda dari tingkat saham hanya sedikit pembedanya.

\section{PEMBAHASAN}

Evaluasi metode DEA Solver dalam penelitian ini merujuk pada tingkat efisiensi saham pada perusahaan makanan dan minuman di Indonesia dengan menggunakan model CCR pada tahun 2017. Hasil tersebut menunjukkan terdapat 2 DMU yang memiliki tingkat efiensi 1 yakni DMU INDF dan DMU ULTJ, ini terjadi karena pada tahun 2017 DMU INDF mengalami kenaikan laba bersih sebesar Rp4,17 triliun atau 0,6\% yang tahun sebelumnya Rp4,14 triliun, bukan itu saja dari sisi penjualan perusahaan netto konsolidasi tersebut sebesar Rp70,19 triliun atau naik senilai 5,3\% dari Rp66,66 triliun pada periode sebelumnya. Sedangkan untuk DMU ULTJ terjadi kenaikan laba bersih sebesar $0,11 \%$ atau Rp703,15 miliar dibandingkan pada periode sebelumnya yang hanya beda tipis yaitu sebesar Rp702,35 miliar pada tahun 2017 bukan laba bersih saja tetapi penjualan juga meningkat yaitu sebesar Rp4,87 triliun atau tumbuh 4,05\% dari tahun sebelumnya.

Pada ranking ke-3 DMU PSDN memiliki score yaitu 0,999 ini terjadi karena pada bulan September 2017 mengalami penurunan penjualan kopi dikarenakan sepanjang tahun 2017 harga biji kopi yang kurang bagus sehingga berdampak pada kinerja keuangan perusahaan. Pada ranking ke-4 DMU SKBM yang memiliki score yaitu sebesar 0,9925 ini terjadi pada bulan Juni 2017 yang mana perusahaan tersebut mengalami penurunan nilai aset keuangan pada perusahaan tersebut. Sedangkan yang terakhir untuk DMU ranking ke-5 dengan score sebesar 0,9868 yaitu DMU ROTI hal itu terjadi karena pada bulan Oktober tahun 2017 kuartal III penurunan atas penjualan sebesar $0,65 \%$, dari sisi pendapatan pun turun yang mana pada tahun 2016 senilai Rp1,84 triliun dan di tahun 2017 senilai Rp1,82 triliun, disisi lain beban usaha juga membengkak dari semula $\mathrm{Rp} 670,77$ miliar menjadi $\mathrm{Rp} 806,78$ miliar. Sehingga laba perusahaan pun ikut merosot, yang mana laba bersih perusahaan tersebut turun hingga 52,21\% year on year (yoy) menjadi Rp97,35 miliar. Padahal periode tahun lalu perusahaan tersebut berhasil mengantongi laba sebesar Rp 203,69 miliar.

\section{KESIMPULAN}

Dari penjelasan diatas dapat disimpulkan bahwa setiap masing-masing DMU perusahaan makanan dan minuman di Indonesia ada yang mengalami penurunan dan ada pula mengalami kenaikan, baik itu dari sisi penjualan, laba bersih, pendapatan penjualan dan sebagainya. Oleh sebab itu, sebaiknya setiap DMU perusahaan makanan dan minuman harus bisa mengelola atau bisa mengatur kinerja laporan keuangan masing-masing perusahaan tersebut agar kinerja laporan keuangan perusahaan tersebut bisa tumbuh sesuai apa yang diharapkan. 


\section{DAFTAR PUSTAKA}

Afrinda, N., 2013. Analisis Pengaruh Likuiditas dan Solvabilitas Terhadap Profitabilitas Perusahaan Makanan dan MInuman Yang Terdaftar Di Bursa Efek Indonesia (BEI). Ekonomi, I(1), p. 4.

Kholis Ernawati, dkk, 2015. Analisis Pengaruh Tingkat Efisiensi Tenaga Kesehatan Terhadap Angka Penemuan Kasusu Tuberkulosis (TB) Paru DI Gorontolo. Kesehatan, I(1), pp. 204-205.

Mutohharo, N. H., 2017. Analisis Efisiensi Pada Perusahaan Sub Sektor Makanan dan Minuman Dalam Indeks Saham Syariah Indonesia (ISSI) Tahun 2012-2015. Islam, I(1), p. 5.

Nugroho J. Setiadi, dkk, 2012. Bisnis Makanan dan Minuman Masih Memikat : Analisis Harga Saham Industri Food And Beverages Di Bursa Efek Indonesia. Accounting and Management, I(1), p. 747.

Rambe, M. F., 2013. Pengaruh Struktur Modal dan Profitabilitas Terhadap Kebijakan Hutang Pada Perusahaan Makanan dan Minuman Di Indonesia. Manajemen \& Bisnis, XIII(1), p. 86.

Suriani Ginting, dkk, 2013. Analisis Faktor-Faktor Yang Mempengaruhi Harga Saham Pada Perusahaan Manufaktur DI Bursa Efek Indonesia. Wira Ekonomi Mikroskil, III(2), p. 62. 